Article

\title{
An E-Tailer's Operational Strategy under Different Supply Chain Structures
}

\author{
Shangyu Pi * and Yang Wang \\ School of Management, Jinan University, Guangzhou 510632, China; 2019wangyang@stu2019.jnu.edu.cn \\ * Correspondence: pishangyu@stu2015.jnu.edu.cn
}

Received: 27 January 2020; Accepted: 6 March 2020; Published: 10 March 2020

\begin{abstract}
Motivated by the enormous business success of E-tailers and their distinct business strategies, this paper analyzes the characteristics of dual online channel competition and the fundamental willingness of an E-tailer to open its marketplace to other retailers while at the same time competing with them. We build game theory models to study the dual-channel competition between an incumbent E-tailer and other online retailers under different supply chain structures. Either the manufacturer or authorized third-party retailers can start an online store in the E-tailer's marketplace. The results show that the transaction fee charged by the platform and the service level provided to customers play significant roles in deciding the marketplace business strategy-the E-tailer faces complicated issues when these two factors fluctuate. A pure strategy of raising the transaction fee may not always be beneficial and a competitor's superior service level may help to enhance a rival's sales price. In the expanded research, dual online channel competition with an unauthorized third-party retailer, which is common in the online marketplace, is also examined.
\end{abstract}

Keywords: e-commerce; platform; supply chain; transaction fee

\section{Introduction}

The global retail sales volume reached 23.956 trillion dollars in 2018, among which the sales volume of e-commerce retailers reached 2.928 trillion dollars, accounting for $12.2 \%$ of the global retail sales volume; this value is expected to reach 4.206 trillion dollars in 2020 [1]. The emergence and explosion of e-commerce have made a vast contribution to society and the economy while facilitating a revolution in distribution and supply chain systems. This open economy focuses on the global market and integrates with the real economy through Internet information technology, big data and artificial intelligence. In the era of big data, the outbreak of the network revolution and the rapid development of logistics are putting the B2B (Business to Business), B2C (Business to Customer) and C2C (Customer to Customer) models of e-commerce development into full swing. The development of the e-commerce and logistics economy is gradually changing traditional methods of trade.

Under the impact of mobile networks, the importance of online channels has been increasing all over the world. Confronting the rapid changes in retail and channel structures, countries have also actively deployed the transformation and upgrading of the retail industry. In terms of the volume of online retail transactions, the top three countries and regions in 2018 were China, with $\$ 1.52$ trillion; the United States, with $\$ 514.8$ billion; and the United Kingdom, with $\$ 128$ billion. Among them, China's online retail transaction scale accounts for $54.7 \%$ of the global online retail transaction scale across 28 major countries and regions. The massive potential of China's consumer market has brought confidence and hope to the recovery of the world economy and the further integration of globalization. China's retail industry, relying on the mature development of e-commerce business and mobile payment technology, has shown rapid growth momentum. The rapid development of China's retail industry also provides fertile soil for the innovation of business models and the application of high-end technology. 
Forrester (2000) shows that $68 \%$ of the manufacturers of consumer goods have already decided to sell their products through the internet directly [2]. In 2019, Forrester forecasted that online spending by direct-to-customer enthusiasts would grow at a compound annual rate of $18 \%$ from 2018 to 2022 [3]. In terms of online channel selection, manufacturers either build direct online channels or delegate online channel expansion to other retailers. Some leading vendors with strong marketing expertise simultaneously own their own online shopping websites and offer their goods and services on other dominant marketplaces. However, the majority of venders choose to join online marketplaces. Amazon and the Alibaba Group are the two leading marketplaces open to vendors, with the former generating $\$ 232$ billion in revenue and later generating $\$ 55$ billion in revenue in 2018. Facing such tremendous business success, we examined the business strategy of the leading marketplaces and surprisingly found that these marketplaces adopt distinct business modes. In this paper, we mainly focus on the business modes of prevalent online marketplaces and determine the opportunities and potential areas that will allow e-players to collaborate.

In the early stage of B2C E-commerce, there are two main business modes: an agency selling (AS) Marketplace and an E-tailer. The AS Marketplace serves as an intermediary platform that only matches supply and demand. It provides a crowded and fully functional platform to venders and a large customer base. For each sale, the AS Marketplace will charge a transaction fee according to the agreed-upon protocol. The vender always owns the procession of the products being sold. The best-known AS marketplace practitioner is Tmall, a subsidiary company of Alibaba Group.

An E-tailer serves as a traditional merchant that procures items from manufacturers and resells them to customers through its website at a profitable price. The E-tailer owns the procession for the sold product. Amazon, a pioneering E-tailer, has primarily been seen as the "Earth's biggest bookstore" since 1995 and became the "Internet's No.1 retailer" in 2000. JD.com, a dual format (DF) marketplace and the second largest e-commerce company in China, is primarily an E-tailer specialized in electronic appliances and digital products.

During the last decade, E-tailers began to provide online platform services to third-party sellers. Third-party sellers use the platform provided by the E-tailer to access customers. These E-tailers operate like traditional merchants, while also associating with other third-party sellers. A hybrid e-commerce mode merges when the E-tailer resells their procured products from manufacturers, while an agent sells the third-party sellers' product at the price of a commission sales fee. It is worth noting that a third-party seller can be any reseller who distributes products or a manufacturer who directly sells products. Martin et al. refer to this business mode as "dual format" retailing (DF) [4]. A critical distinction between the reselling and agency selling formats is who sets the retail price. In agency selling, the retail price is decided by the manufacturer, whereas in reselling, it is decided by the E-tailer. A perfect example of the DF retailing marketplace is Amazon. Amazon launches its Marketplace to the public in 2001 and later provided Fulfillment by Amazon (FBA) to its marketplace players in 2007. FBA provides retailers a sophisticated order fulfillment service, from order placement, to warehousing management, to the final distribution to customers. There are more than two million retailers that participate in the Amazon Marketplace. The sales from these retailers are almost the same as those of Amazon merchant sales. JD.com's logistics network also has a successful reputation. It not only serves JD.com's E-tailer business but also provides order fulfillment services to the manufacturers and third-party retailers. In 2019, JD.com owned 61\% of the market share of electronic appliances online and $58 \%$ of the market share of infant formula milk powder among online and offline platforms. Table 1 shows the channels of the top brands sold on JD.com in different industry sectors. 
Table 1. Channels of the top brands sold on JD.com in different industry sectors.

\begin{tabular}{|c|c|c|c|c|}
\hline \multirow{2}{*}{ Industry } & \multirow{2}{*}{ Manufacturer } & \multicolumn{3}{|c|}{ Channels on JD.com } \\
\hline & & JD E-Tailer & Manufacturer Direct Selling & 3P Retailing \\
\hline \multirow{5}{*}{$\begin{array}{l}\text { Electronic } \\
\text { Appliances }\end{array}$} & Gree & $\sqrt{ }$ & $\sqrt{ }$ & $\sqrt{ }$ \\
\hline & Haier & $\sqrt{ }$ & $\sqrt{ }$ & $\sqrt{ }$ \\
\hline & Midea & $\sqrt{ }$ & $\sqrt{ }$ & $\sqrt{ }$ \\
\hline & Simens & $\sqrt{ }$ & $\sqrt{ }$ & $\sqrt{ }$ \\
\hline & Panasonics & $\sqrt{ }$ & - & $\sqrt{ }$ \\
\hline \multirow{4}{*}{ Smartphone } & Apple & - & $\sqrt{ }$ & $\sqrt{ }$ \\
\hline & Huawei & - & $\sqrt{ }$ & $\sqrt{ }$ \\
\hline & Xiaomi & - & $\sqrt{ }$ & $\sqrt{ }$ \\
\hline & Vivo & - & $\sqrt{ }$ & $\sqrt{ }$ \\
\hline \multirow{5}{*}{$\begin{array}{l}\text { Infant formula } \\
\text { milk powder }\end{array}$} & Aptamil & $\sqrt{ }$ & $\sqrt{ }$ & $\sqrt{ }$ \\
\hline & Mead Johnson & $\sqrt{ }$ & $\sqrt{ }$ & $\sqrt{ }$ \\
\hline & Wyeth & $\sqrt{ }$ & $\sqrt{ }$ & $\sqrt{ }$ \\
\hline & Nutrilon & $\sqrt{ }$ & $\sqrt{ }$ & $\sqrt{ }$ \\
\hline & A2 & $\sqrt{ }$ & 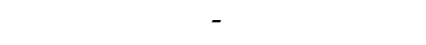 & $\sqrt{ }$ \\
\hline
\end{tabular}

It is worth noting that the majority of electronic appliance and digital product manufacturers partially choose JD.com's order fulfillment service. However, most of the smartphone manufacturers have no willingness to directly sell their products on a dual-format marketplace. Infant formula milk powder and other consumable goods are preferred to have a full presence on the marketplace, so their manufacturers choose JD.com's order fulfillment service.

There are significant differences between e-commerce and traditional retailing. In traditional retailing, the market scope is relatively concentrated. As long as the traditional retailing is successful in some market sections, it can live long in the market. However, in the development of the online marketplace, the business scope and boundary of the market are changing rapidly. The market has become infinite and the competition between the marketplaces has become more intense. In recent years, more and more e-commerce companies have sprung up but they have also gone fast in the market. The online marketplace business has formed a winner-take-all situation. Under the squeeze of e-commerce giants, other e-commerce companies face strategic confusion in the process of development.

Meanwhile, for giants, because online customers have less viscosity, they also have to consider sustainable development strategy. When facing the rapid change of customer preference or public emergency, the present strategy advantage can soon become a disadvantage and surplus by another e-commerce firm with a different business model. A forward-looking and sustainable strategy will guide a firm to operate through the transformation. In the COVID-19 epidemic, Internet users who can only stay at home have released their consumption enthusiasm on the internet, making the online service industry such as e-commerce and logistics usher in a massive wave of "opportunities" for growth in a short term. However, not every online marketplace can seize the opportunity. With a strong self-built logistic network, JD.com predicts the first season sales growth rate will reach double-digit. However, the sales of JD.com's primary competitor, Alibaba and Pinduoduo, have dropped due to a staff shortage of the cooperate logistics companies. The only platform with self-built logistics can deliver to the customers on time. Under the epidemic, customers, suppliers and retailers realize the importance and superiority of JD.com's business model, although JD.com's logistics sector has just reached a break-even point. In the long-run, a self-built logistic network and in-depth supplier cooperation provide the eco-system of JD.com a sustainable development.

In this article, we consider a manufacturer that wholesales its products to downstream e-retailers but may also choose to participate in a platform system. The E-tailer can choose to only operate as an online merchant or it can open its platform to other vendors in a dual format mode. For instance, Amazon primarily serves as an online merchant but later open its Amazon Marketplace to a substantial 
number of vendors, including manufacturer and retailers. Manufacturers and third-party sellers can sell their products directly to consumers at the expense of a transaction fee per sale to the platform.

Motivated by the enormous business success of these marketplaces and their very distinct business strategy, we analyze the characteristics of the different types of marketplace competition and the fundamental willingness of the marketplace in opening its platform to other vendors while at the same time competing with those vendors. Moreover, if the E-tailer is willing to open its platform, what is the E-tailer's decision regarding whether to sell a competing product? How should the E-tailer price that competing product and how should it design its contract with the marketplace members? We are also interested in this problem from the perspective of vendors. How will the manufacturer and third-party sellers choose their online channels? In this work, we build dual-channel game theory models for relevant online marketplace competition. Our aim in this paper is to develop a deeper understanding of online marketplace selection and marketplace business strategies.

Our results show that the transaction fee charged by the platform and the service level provided to customers play significant roles in deciding the marketplace business strategy-an E-tailer faces a complicated dilemma when these two factors fluctuate. A pure strategy of raising the transaction fee may not always be beneficial and a competitor's better service level may help to enhance a rival's sales price. These results offer inspiring insights that could provide a theoretical explanation for the existence of various e-commerce business modes and mechanisms.

The remainder of the paper is arranged as follows: We review the relevant literature in the next section. In Section 3, we describe the research problems and then analyze the channel structures under different marketplace business strategies. In Sections 4 and 5, we build game theory models and provide the analytical results for different channel structures, respectively. In Section 6, we expand our work to an unauthorized third-party reseller scenario and explain why a platform sometimes turns a blind eye to manufacturer complaints. We conclude with managerial implications, limitations and future modeling efforts in Section 7.

\section{Literature Review}

This paper is closely related to three streams of literature: (i) dual-channel supply chain, (ii) price and service coordination and (iii) marketplace and platform.

\subsection{Dual-Channel Supply Chain}

Our paper is related to the literature on the dual-channel supply chain. Unlike the work on single supplier and competing retailer supply chains $[5,6]$, the research on the dual-channel supply chain mainly focuses on the competition and conflict coordination between hybrid e-channel and physical retail. Along with the rolling stream through which manufacturers expand their business via e-commerce, abundant research has flourished on the dual-channel supply chain. It is important to consider price competition between the direct channel and retailers, as price is the decision variable [7-10]. Supposing that the product price is fixed, some studies focus on the inventory competition [11,12], optimal service level or sales efforts in channel coordination [13,14]. Tiaojun Xiao and Jim (Junmin) Shi [15] considered the pricing and channel priority strategies of a dual-channel supply chain in the presence of a supply shortage caused by random yields.

Cai [16] determined that suppliers and retailers will both benefit from introducing a direct selling channel to the conventional channel and that the supplier will benefit more strongly from a dual-channel structure by gaining stronger bargaining power. Lu and Chen Yingju [17] found that when the manufacturer directly sells through an e-channel, more online customers are attracted to the manufacturers' bricks-and-mortar shop; this can also facilitate a double marginalization problem. Ha et al. [18] discussed the conditions under which a manufacturer exploits the direct selling channel when a product's quality is different in different channels. The authors found that when the cost of direct selling and product quality enhancement is relatively low, the manufacturer should develop a direct selling channel. Kenji Matsui [19] investigated the timing problem concerning when a manufacturer 
managing a dual-channel supply chain should post the wholesale price and direct price. The authors demonstrated that simultaneous price competition never arises if the manufacturer and retailer can choose not only the level of the price but also the timing of the pricing. The authors suggest that the manufacturer should post the direct price before or upon but not after, setting the wholesale price for the retailer.

Batarfi et al. [20] investigated the effect of adopting a dual channel that consists of a traditional retail channel and a direct online channel on the performance of a two-level supply chain. They found that the manufacturer likes to offer customized products through a direct online channel in addition to providing its standard product through a traditional retail channel. Different from the manufacturer's perspective, some research also draws upon the retailer's perspective. Zhang et al. [21] study a retailer's channel structure choice and pricing decisions in a supply chain with a manufacturer and a retailer. One of their interesting findings is that a pure offline retailer may strategically establish an online channel with little demand to gain whole price reductions from the manufacturer. Nie et al. [22] investigated the impacts of cross-channel effects on the two competing traditional retailers' distribution channel strategies. They found that when the cross-channel effect is significantly negative, the retailers may give up their online and offline strategies. When the cross-channel effect is not significantly negative or positive, both retailers prefer an online-offline strategy, even if it may involve the prisoners' dilemma.

\subsection{Price and Service Coordination}

There are also studies on price and service level (i.e., product quality and delivery time) coordination in channel competition [23]. Yan et al. [24] found that even when there are no direct sales through the direct channel, manufacturers can use the direct channel as a useful tool to motivate the retailer to improve their services so that the manufacturer can directly profit from the improved retail service. Modak et al. [25] examined a traditional retail channel with a direct online channel under price and delivery-time dependent stochastic customer demands. Xu et al. [26] considered five decision variables, as well as the price and order quantity for both the retail and the online channels and the delivery time for the online channel. They extended the work of Chiang et al. [9] by investigating how price and deliver lead time decisions affect channel configuration strategies under either the manufacturer-owned or the decentralized model. Some research draws on the idea of green supply. Qi et al. [27] considered the coordination of a dual-channel supply chain under mandatory carbon emission capacity regulation. $\mathrm{Xu}$ et al. [28] focused on low-carbon preferences and channel substitution under cap-and-trade regulations in dual-channel coordination.

\subsection{Marketplace and Platform}

Our research is also relevant to literature on the selection of marketplaces and platforms. Marketplaces, a rapidly emerging category of platforms, enable and support transactions between independent supply and demand-side participants (McIntyre and Srinivasan [29]), trigger network effects between demand and supply and have the potential to dominate the market with a winner-take-all dynamic. Internet-based marketplace research has taken place since the late 1990s [30,31]. These studies focused on the procurement efficiency within a particular industrial environment. Along with the development of new technology, big data, advanced matching algorithms and mobile device popularity have enabled the development of innovative marketplace business models.

Research on platform retailing is still in its initial stages compared to fruitful e-commerce marketing research [32]. The most plentiful related work involves the strategic choice of marketplace retailing mode and channel choice in hybrid platform retailing. Täuscher et al. [33] provided a conceptually and empirically grounded taxonomy of the leading digital platforms and analyzed 100 randomly selected marketplaces via content analysis and binary coding. The authors showed that there is no one-size-fits-all approach to creating, delivering and capturing value with marketplaces and platforms in general. Also, they determined that commission fees, subscription fees, advertising and service sales are the key revenue streams of the marketplace. Commissions are the primary option for $\mathrm{C} 2 \mathrm{C}$ 
(79\%) and B2C (70\%) marketplaces. Muzellec et al. [34] visualized internet intermediaries as resource integrators, involving consumers and business partners in the co-creation process of a value-adding, integrated, two-sided model. They analyzed five early-stage internet ventures and found that the business models of these ventures show a clear pattern of evolution from inception to maturity, from B2C towards B2B and ultimately to an integrated combination.

Regarding the strategic choice of platform retailing mode, Hagiu [35] provided the first comparison between two polar strategies (reselling and agent selling) for market intermediation by analyzing the indirect network effects between buyers and sellers, asymmetric information between the seller and the intermediary and investment incentives and product complementarities/substitutability. Ryan [36] provided the conditions under which a retailer that currently sells its product through its website should expand its market to the marketplace. They analyzed the optimal decisions for both the retailers and marketplace firms and characterized the system's equilibrium. Mantin et al. [4] investigated a third-party marketplace that both resells and provides access to other third-party sellers to access and compete for the same customers by adopting a dual-format model. They investigated the strategic rationale for a retailer to introduce a 3P marketplace. Hagiu and Wright [37] studied the intermediary's different outcomes under two polar strategies, considering who has the control rights over a non-contractible decision variable. The above research has not reached the point that an E-tailer may participate as a merchant while also providing platform service to other retailers. Abhishek et al. [38] studied a single manufacturer and two independent E-tailer supply chains and analyzed their retailing mode decisions under different retailing externalities. They suggested that agency selling is an efficient selling format. However, whether an E-tailer should adopt this mode of selling depends on the extent of the demand spillover between the online channel and the conventional channel, as well as the level of competition between e-tailers. Tian et al. [39] examined how both upstream competition and order-fulfillment costs moderate the choice of channel mode for the online intermediary. They found that when the upstream competition is very intense or the order fulfillment cost is high, the revenue sharing scheme adopted by many online platforms does not always outperform the traditional reseller model. By analyzing the market strategy and market impact of two giant e-book retailers, Amazon and Apple, Anderson et al. [40] discussed the circumstances under which an E-tailer should choose agent selling. In the same context, motivated by Apple's choice of an agency model when entering the e-book market, Wirl [41] provided the inner mechanism to explain Apple's decisions and the possibility of asymmetrical equilibrium. The above research assumes that the agency mode and reselling mode are mutually exclusive, that an E-tailer will choose a single strategy and that the manufacturer has a single distribution channel on the E-tailer's platform.

Our paper differs from extant publications in several ways. First, we focus on online channel competition. Previous studies on the channel competition domain have mostly focused on the introduction of the online channel to offline channels. Second, the dual online channel we focus upon is built on a single platform. The E-tailer, manufacturer and third-party reseller remain in the same ecosystem on the platform. Third, we identify that transaction fees in the revenue sharing regime are a critical factor in a platform's online channel competition. This factor is irrelevant to the introduction of a direct channel to an indirect channel. Some studies have considered channel coordination with revenue sharing in the direct versus indirect channel domain. Recently, Wang et al. [42] also studied the alternative internet channel entry option for a third-party online marketplace. However, the explanations of revenue sharing in the indirect versus direct channel perspective do not apply to online marketplace competition.

\section{Problem Description and Channel Structure}

In this section, we first describe our research problem and then analyze channel structures under different marketplace business strategies to derive the demand functions for the manufacturer. 


\subsection{Problem Description}

We consider an E-tailer (she) who sells goods through her website as a conventional merchant and, affected by the E-era trend, is willing to open her website as a marketplace to other retailers. She possesses a broad customer base because of her well-perceived service quality and long-established reputation. A manufacturer (he), who used to wholesale his product solely to retailers, now has a choice to join the marketplace and develop a direct channel. Alternatively, he can choose to distribute his product through a third-party reseller on the E-tailer's marketplace. Facing different retail channel choices, the customers make their decisions according to various factors, such as price, perceived product quality and service quality. Each party decides the quality for the channel it operates-i.e., the E-tailer chooses $q_{E}$, whereas the manufacturer chooses $q_{M}$. The E-tailer charges a fraction $\theta, 0 \leq \theta \leq 1$, from other retailers' revenues as a transaction fee for accessing the marketplace. This type of fee structure is commonly used by many online platforms, such as Taobao, Amazon Marketplace, JD and the Apple App Store. Therefore, as both a platform provider and a merchant, it is essential for the E-tailer to configure an appropriate platform structure.

Customers are strategic and their purchase choices are based on utility maximization [36]. We assume that customers have different product valuations, $v$, where $v$ is uniformly distributed in the interval, $[0,1]$. We assume that customers prefer to purchase from the E-tailer because of her long-established reputation and better service (i.e., a shorter delivery time, complete packaging and better after-sale service). Therefore, all customers incur a disutility, $1-\mathrm{s}$, when purchasing from another channel than the E-tailer. Thus, given that the product is identical, we follow the established norms in the operations literature [9]. The utility functions of the E-tailer, manufacturer and the third-party reseller are: $U_{E}=v-p_{E}, U_{M}=s v-p_{M}$ and $U_{A}=s v-p_{A}$, respectively, where $U_{i}$ and $p_{i}$ refer, respectively, to the utility and price of the product selling in a different channel $i(=\mathrm{E}, \mathrm{M}, \mathrm{A})$.

\subsection{Channel Structures}

The E-tailer, manufacturer and third-party reseller build their relationship based on different contractual arrangements. In the initial stage of e-commerce, the E-tailer always purchases product from the manufacturer at a wholesale price and resells the product to end-customers at a higher retail price. The fundamental process is similar to that of brick-and-mortar retail but the transaction is located online, with procedures that still require fixes. Along with the prevalence of the dual format in recent years, E-tailers have started to widely open their channels as a marketplace for other retailers. The manufacturer who used to wholesale his products is willing to take a chance in the e-commerce era and build his own direct channel in the marketplace. Alternatively, he can invite a third-party reseller to the marketplace and compete with the E-tailer. Thus, the E-tailer can either choose reselling, agency selling or both formats. For ease of exposition, we use the pronoun "she" to represent the E-tailer, "he" to denote the manufacturer and "it" to describe the third-party reseller in the remainder of the study.

We next specify the sequence of events and decisions in our model. The E-tailer is always the first to decide whether to offer platform services to other retailers. The sequence of the subsequent events depends on E-tailer's decisions, as follows:

- If the E-tailer chooses not to offer the platform service, the manufacturer will only wholesale its product to the E-tailer. Other third-party retailers have no chance to participate in this competition. In this case, the manufacturer only gives the wholesale price $w$ to the E-tailer and the E-tailer sells to end customers.

- If the E-tailer offers a platform service, the E-tailer must decide the contractual terms with the manufacturer and other retailers who want to join the marketplace. Specifically, the E-tailer must decide the transaction fee it charges to the manufacturer. Thereafter, the manufacturer decides whether to directly sell in the marketplace. If the manufacturer directly sells through the marketplace, he will wholesale his product to the E-tailer and also compete with the E-tailer on the marketplace. 
- If the E-tailer offers a platform service and the manufacturer does not want to join the marketplace, the third-party retailer will sell through the marketplace. Both the E-tailer and the third-party retailer purchase products from the manufacturer.

Based on the various decisions made by the E-tailer and manufacturer, there are several channel structures, defined as follows (also see Figure 1).

- E-merchant mode EM: The E-tailer chooses not to open a platform service. She purchases from the manufacturer and resells to end customers through an online channel (refer to Figure 1a).

- Dual format mode PM: The E-tailer chooses to provide a platform service by specifying a transaction fee and still acts as a reseller. The manufacturer decides to directly sell the product on the platform (refer to Figure 1b).

- Dual format mode PA: The E-tailer performs the same as in the PM mode; however, a third-party will agent sell the product on the marketplace instead of the manufacturer (refer to Figure 1c).

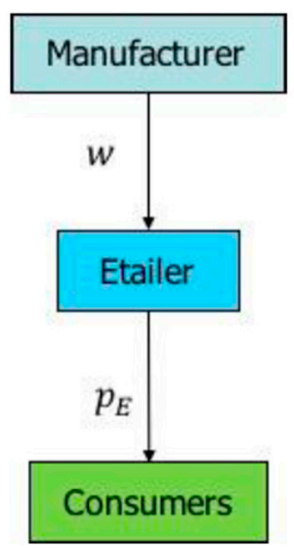

(a)

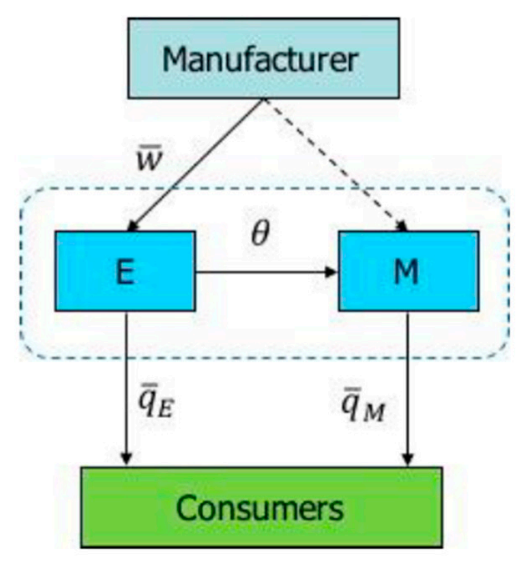

(b)

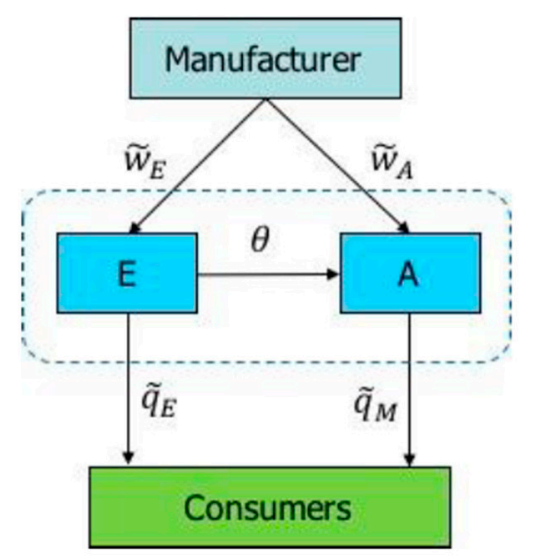

(c)

Figure 1. Different dual online-channel structures: (a) E-merchant mode (EM), (b) Dual format Platform-Manufacturer mode (PM), (c) Dual format Platform-Agent mode (PA).

\section{Equilibrium Analysis}

The first set of results described below is our benchmark-setting, where the E-tailer serves as an online merchant (mode EM). Next, we consider the setting where the E-tailer opens its platform service to the public and the manufacturer decides whether to join the platform (mode PM).

\subsection{Mode EM}

In this base mode, the E-tailer chooses not to provide a platform service to the public. The E-tailer purchases the product at a wholesale price $w$ from the manufacturer and determines the quantity $q_{E}$. This is a simple monopoly situation. The demand function of E-tailer is:

$$
q_{E}=1-p_{E}
$$

The profits for the E-tailer and the manufacturer are as follows:

$$
\begin{gathered}
\pi_{E}=\left(p_{E}-w\right) q_{E} \\
\pi_{M}=q_{P} w .
\end{gathered}
$$

The equilibrium quantity, price and wholesale price under this configuration are $q_{E}^{*}=\frac{1}{4}, p_{E}^{*}=\frac{3}{4}$ and $w^{*}=\frac{1}{2}$. The equilibrium payoffs are $\pi_{M}^{*}=\frac{1}{8}, \pi_{E}^{*}=\frac{1}{16}$. 
In Mode EM, the E-tailer's role is fundamentally the same as that of a traditional merchant. Only her business activities are developed on the internet-based infrastructure platform. The three-level supply chain formed by the manufacturer, the E-tailer and the end customers is mostly similar to that of the physical retail industry.

\subsection{Mode PM}

In Mode PM, the E-tailer provides a platform service to the manufacturer. The manufacturer decides to join the platform and directly sell to end customers. He pays the transaction fee to the E-tailer and accepts the market structure. Meanwhile, the manufacturer wholesales his product to the E-tailer.

The inverse demand functions of the E-tailer and manufacturer are

$$
\begin{gathered}
\bar{q}_{E}=1-\frac{\bar{p}_{E}-\bar{p}_{M}}{1-s} \\
\bar{q}_{M}=\frac{\bar{p}_{E}-\bar{p}_{M}}{1-s}-\frac{\bar{p}_{M}}{s} .
\end{gathered}
$$

The inverse demand function and profits for the E-tailer and the manufacturer are as follows:

$$
\begin{gathered}
\bar{p}_{E}=1-\bar{q}_{E}-s \bar{q}_{M} \\
\bar{p}_{M}=s\left(1-\bar{q}_{M}-\bar{q}_{E}\right) \\
\bar{\pi}_{E}=\left(\bar{p}_{E}-\bar{w}\right) \bar{q}_{E}+\theta \bar{p}_{M} \bar{q}_{M} \\
\bar{\pi}_{M}=\bar{q}_{E} \bar{w}+(1-\theta) \bar{p}_{M} \bar{q}_{M} .
\end{gathered}
$$

We solve this game using backward induction. For the given wholesale price w, we first characterize the equilibrium quantity that would maximize $\pi_{E}$. The equilibrium quantities under this configuration are as follows:

$$
\begin{gathered}
\bar{w}^{*}=\frac{8-(4+8 \theta) s+(1+\theta)^{2} s^{2}}{2(8-(3+\theta) s)} \\
\overline{\mathrm{q}}_{\mathrm{E}}^{*}=\frac{2(1-\mathrm{s})}{(8-(3+\theta) \mathrm{s})} \\
\bar{q}_{M}^{*}=\frac{6-(1+\theta) s}{2(8-(3+\theta) s)} .
\end{gathered}
$$

The equilibrium payoffs are as follows:

$$
\begin{gathered}
\bar{\pi}_{E}^{*}=\frac{16-4(8-15 \theta) s-8\left(2 \theta^{2}+5 \theta-2\right) s^{2}+\theta(1+\theta)(5+\theta) s^{3}}{4(8-(3+\theta) s)^{2}} \\
\bar{\pi}_{M}^{*}=\frac{4-8 \theta s+(1+\theta)^{2} s^{2}}{4(8-(3+\theta) s)} .
\end{gathered}
$$

From the above equilibrium, we observe that the transaction fee of the E-tailer is a significant influencer of the channel's structure. When the transaction fee is low, the manufacturer will offer a higher wholesale price to the E-tailer. Conversely, the E-tailer's sales volume will decrease while the transaction fee is high. In return, the manufacturer will capture the missing sales volume. There will be a consumption switch from the E-tailer to the manufacturer according to the openness of the platform. Although the E-tailer will lose partial sales, she will gain more transaction fees from the manufacturer, which will largely compensate and exceed this loss of sales. It is thus beneficial for the E-tailer to open 
her platform service. This result explains why major E-tailers open their platforms and share their channel resources with other retailers.

Along with an increase in the transaction fee, the manufacturer's product price and sales volume will drop. The wholesale price for the E-tailer will also decrease, leading to a higher wholesale volume. This result will also compensate for the loss of the manufacturer.

It is straightforward to discern that when the competition between the manufacturer and E-tailer is severe (in other words, if they offer similar services), the payoffs for the E-tailer and manufacturer will be $\bar{\pi}_{E}^{*}=\frac{\theta}{4}, \bar{\pi}_{M}^{*}=\frac{1-\theta}{4}$ (when s =1). Comparing the E-tailer and manufacturer's payoffs in Mode EM and Mode PM under the same service level, we have: when $\frac{1}{4} \leq \theta \leq \frac{1}{2}, \bar{\pi}_{E}^{*} \geq \pi_{E}^{*}$ and $\bar{\pi}_{M}^{*} \geq \pi_{M}^{*}$. Namely, if the customer's channel preference is weak and the manufacturer can improve his service to reach the level of the E-tailer and if the proportion fee charged by the E-tailer is moderately high, then both of the parties will benefit more than by choosing Mode EM. The E-tailer prefers to provide a platform service and the manufacturer gains more profit through both wholesale and direct selling on the platform.

When the manufacturer and the E-tailer provide different service levels, there will be two cases to consider for the payoff of the manufacturer.

Lemma 1. If $\theta \leq \frac{1}{5}$, then $\bar{\pi}_{M}^{*}>\pi_{M}^{*}$. If $\theta>\frac{1}{5}$ and $s \leq \frac{3(5 \theta-1)}{2(1+\theta)^{2}}$, then $\bar{\pi}_{M}^{*}<\pi_{M}^{*}$.

When the proportion fee is small, the manufacturer will benefit from joining the platform no matter how the market competition varies. When the proportion of the fee becomes higher, the manufacturer's profits will be extracted more strongly by the E-tailer. Thus, there exists $s \leq \frac{3(5 \theta-1)}{2(1+\theta)^{2}}$, where the manufacturer will be harmed by joining the platform.

From the above analysis, we have the following:

Theorem 1. When $\frac{1}{4}<\theta<\frac{23-6 \sqrt{10}}{13}$ and $\frac{1}{8}\left(-\frac{11}{\theta}+\frac{39}{1+\theta}+\frac{37}{5+\theta}+\frac{(5-\theta) \sqrt{121-426 \theta+129 \theta^{2}}}{\theta(1+\theta)(5+\theta)}\right)<<1$, when or $\frac{23-6 \sqrt{10}}{13}<\theta<\frac{1}{2}$ and $\frac{3(5 \theta-1)}{2(1+\theta)^{2}}<s<1$, the E-tailer will provide a platform service and the manufacturer will join the platform.

Under Theorem 1, although the E-tailer and manufacturer will compete with each other on the platform, they will benefit more from a simple vertical three-tier supply chain configuration.

\subsection{Mode EA}

In this setting, the E-tailer will still offer the online marketplace to the public. However, the manufacturer will not participate in the direct selling process. This choice may be related to the manufacturer's business strategy or resource competence. The manufacturer, therefore, would like to invite a third-party seller to the marketplace and authorize this third-party agent to sell his product. Hence, the manufacturer will wholesale his product at the wholesale price $w$ to the E-tailer $\left(\tilde{w}_{E}\right)$ and the authorized third-party seller $\left(\tilde{w}_{A}\right)$ and the above two sellers will compete with each other on the same platform. Because the third-party seller is using the E-tailer's platform service and is exposed to the E-tailer's customers, the third-party will have to pay a transaction fee for the platform service. In this case, the manufacturer will only be the product supplier and not responsible for any distribution functions.

The inverse demand functions of the E-tailer and third-party reseller are

$$
\begin{gathered}
\tilde{q}_{E}=1-\frac{\tilde{p}_{E}-\tilde{p}_{A}}{1-s} \\
\tilde{q}_{A}=\frac{\tilde{p}_{E}-\tilde{p}_{A}}{1-s}-\frac{\tilde{p}_{A}}{s} .
\end{gathered}
$$


The inverse demand function and profits for each participant under this mode are as follows:

$$
\begin{gathered}
\tilde{p}_{E}=1-\tilde{q}_{E}-s \tilde{q}_{A} \\
\tilde{p}_{A}=s\left(1-\tilde{q}_{A}-\tilde{q}_{E}\right) \\
\tilde{\pi}_{E}=\left(\tilde{p}_{E}-\tilde{w}_{E}\right) \tilde{q}_{E}+\theta \tilde{p}_{A} \tilde{q}_{A} \\
\tilde{\pi}_{A}=\left((1-\theta) \tilde{p}_{A}-\tilde{w}_{A}\right) \tilde{q}_{A} \\
\tilde{\pi}_{M}=\tilde{q}_{E} \tilde{w}_{E}+\tilde{q}_{A} \tilde{w}_{A} .
\end{gathered}
$$

We solved this game by simultaneously determining the retailer prices. The results are shown below:

$$
\begin{gathered}
\tilde{w}_{E}^{*}=\frac{(1-\theta)(4-(1+2 \theta) s)}{2(4(1-\theta)-s)}, \tilde{w}_{A}^{*}=\frac{(1-\theta) s((2-\theta)-(1+\theta) s)}{2(4(1-\theta)-s)} \\
\tilde{p}_{E}=\frac{6(1-\theta)-(2-\theta) s}{2(4(1-\theta)-s)}, \tilde{p}_{A}=\frac{s((5-4 \theta)-(1+\theta) s)}{2(4(1-\theta)-s)} \\
\tilde{\pi}_{E}^{*}=\frac{4(1-\theta)^{2}-\left(4-15 \theta+24 \theta^{2}-12 \theta^{3}\right) s+\left(1-4 \theta+5 \theta^{2}\right) s^{2}}{4(4(1-\theta)-s)^{2}} \\
\tilde{\pi}_{A}^{*}=\frac{(1-\theta)(1-2 \theta)^{2} s}{4(4(1-\theta)-s)^{2}} \\
\tilde{\pi}_{M}^{*}=\frac{(1-\theta)(1-\theta s)}{2(4(1-\theta)-s)} .
\end{gathered}
$$

We first examine how transaction $\theta$ influences the channel structure.

Lemma 2. (1) $\frac{\partial \tilde{\mathrm{w}}_{\mathrm{A}}}{\partial \theta}<0$, if $\frac{2-\sqrt{2}}{2}<\theta<\frac{1}{2}$ and $0<\mathrm{s}<\min \left\{1, \frac{4-16 \theta+8 \theta^{2}}{1-4 \theta}\right\}$, then $\frac{\partial \tilde{\mathrm{w}}_{\mathrm{E}}}{\partial \theta}>0$; if $0<\theta<$ $\frac{2-\sqrt{2}}{2}$ and $\max \left\{0, \frac{4-16 \theta+8 \theta^{2}}{1-4 \theta}\right\}<\mathrm{s}<1$, then $\frac{\partial \tilde{\mathrm{w}}_{\mathrm{E}}}{\partial \theta}<0$;

(2) $\frac{\partial \tilde{\mathrm{q}}_{\mathrm{E}}}{\partial \theta}>0, \frac{\partial \tilde{\mathrm{q}}_{\mathrm{A}}}{\partial \theta}<0$;

(3) $\frac{\partial \tilde{p}_{E}}{\partial \theta}>0, \frac{\partial \tilde{p}_{A}}{\partial \theta}>0$;

(4) $\frac{\partial \tilde{\pi}_{A}^{*}}{\partial \theta}<0, \frac{\partial \tilde{\pi}_{M}^{*}}{\partial \theta}<0$.

Along with an increase of the transaction fee, the manufacturer's wholesale price for the third-party retailer will decrease. When the transaction fee is low, the third-party has greater motivation to sell the product and the manufacturer will gain more profit because of the higher wholesale price. When the transaction fee is moderate and the service level between the third-party reseller and the E-tailer are significantly different, the manufacturer's wholesale price to the E-tailer will increase along with an increase in the transaction fee. Under the same moderate transaction fee, if the third-party reseller's service level can match the E-tailer's, the E-tailer can obtain a lower wholesale price along with an increase in the transaction fee. The cost of the E-tailer will thus be saved. When the transaction increases, because the E-tailer gets a higher wholesale price from the manufacturer, in return, she will raise the product's price. Meanwhile, the third-party reseller will also raise the product's price to mitigate the cost pressures produced by the higher transaction cost. Because of the overall decrease in sales volume, the manufacturer will also be harmed.

When we consider the benefit of all the players, we can draw the following conclusion. When the transaction fee is low, although the E-tailer's sale volume will decrease, her overall profit will increase. When the transaction fee is high, the E-tailer's profit will decrease along with an increase in the transaction fee. This result occurs because the transaction fee is configured by the sales volume. 
A decrease in the third-party reseller's volume leads to a lower transaction fee income for the E-tailer. Although there will be an increase in the E-tailer's own sales volume, this increase cannot compensate for the losses from the transaction fee. Only when the transaction fee is moderate and the service levels of the E-tailer and the third-party reseller are indifferent will the E-tailer's overall profit increase along with increases in the transaction fee. This result will help E-tailers understand the role of the transaction fee and cautions that a high transaction fee cannot always yield a higher profit.

From the above analysis, we obtain theorem 4.2, as follows:

Theorem 2. When $\frac{1}{4}<\theta<\frac{9-\sqrt{33}}{12}, \frac{8-36 \theta+24 \theta^{2}}{3-10 \theta}<s<1$ or $\frac{9-\sqrt{33}}{12}<\theta<1$, the E-tailer will open her platform to other retailers. The manufacturer will also authorize third-party resellers to join the platform to expand his channels.

\section{Numerical Simulation and Analysis}

This section verifies the above equilibrium results through numerical simulation. The impact of the platform transaction fee and service level of each party provided will be examined. Meanwhile, we will discuss the cooperation opportunities between the E-tailer platform and manufacturers under different business modes. As the dual-format retailing are adopted by the prevalent marketplaces, we focus on the PM and PA mode analysis. Further we will analyze the operational characteristics of the E-tailer platform.

\subsection{Dual-Format PM Mode}

Based on the three-dimensional Figure 2, the equilibrium result affected by the transaction fee and the manufacturer's service level is shown.

When the E-tailer opens his platform, the E-tailer's sales volume increases as the transaction fee increases. When the manufacturer's service level increases, the E-tailer will face severe competition and her sales volume will decrease. Conversely, the manufacturer's sales volume will decrease as his transaction fee increases and will increase as the E-tailer's service level is enhanced. This result shows that the platform and manufacturer are substitutable with each other. Either of the two parties' sale efforts will provide the other with an inevitable market loss.

When examining the product price, we observe that the manufacturer's product price will be lower as his transaction fee increases. When the manufacturer enhances his service level, the E-tailer's product price will be more complex as the transaction fee and the manufacturer's service level vary. The influence on the product price from either of these factors will be affected by the other factor. The service level will indicate the complementary strategy for pricing. This result might lead to a phenomenon in which one player will increase its product price, while the other player will increase its service level.

The E-tailer's overall profit remains generally stable with a slight fluctuation in a small range due to the influence of transaction fees and service level. When the competitor's service level increases, the transaction fee will have a potent impact on the E-tailer's profit. At this stage, the E-tailer's decisions must be more flexibly aligned with the competitor's movement. In order to avoid severe market competition, the E-tailer can facilitate competition by adjusting her transaction fee setting. 

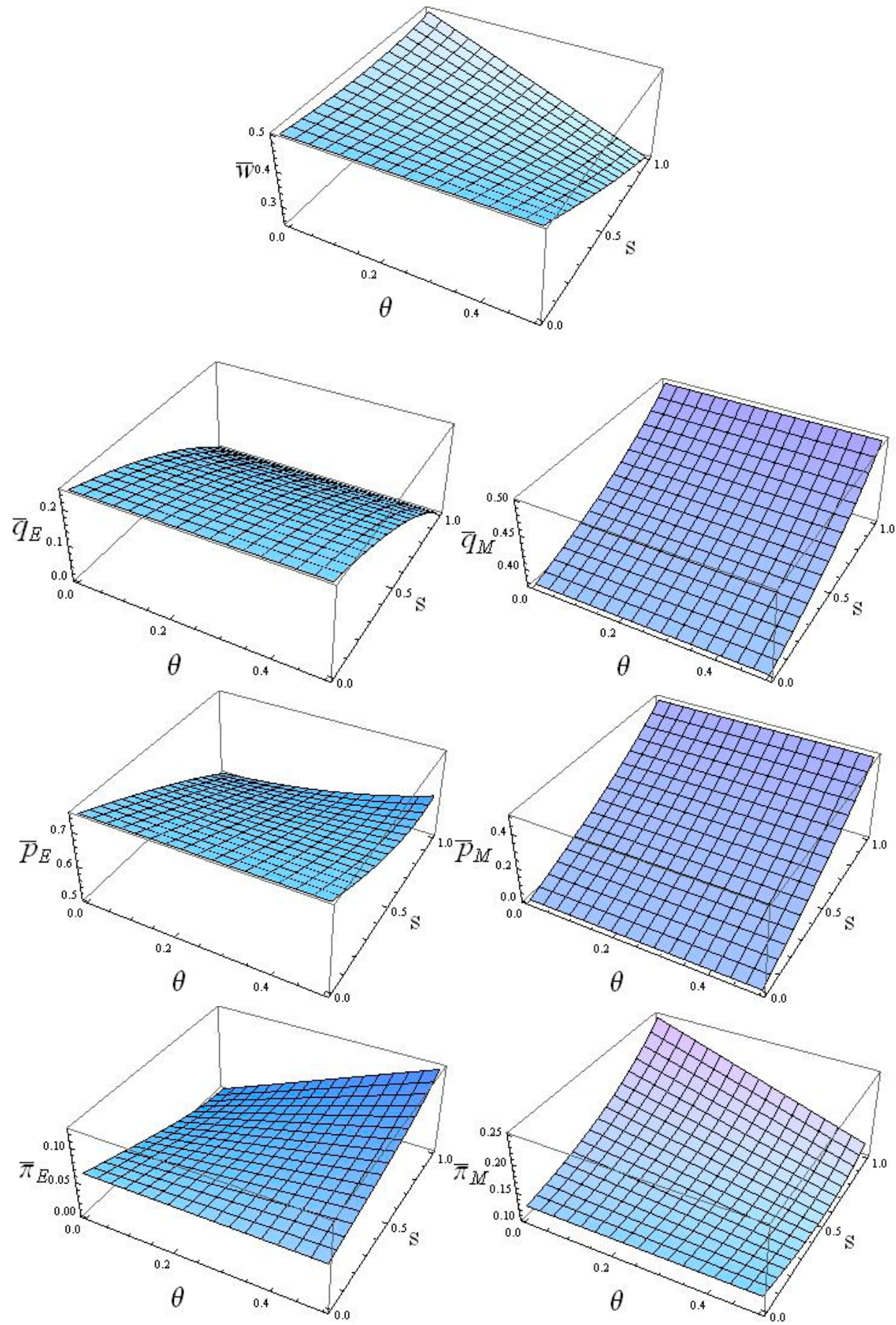

Figure 2. Equilibrium in Platform-Manufacturer mode.

\subsection{Dual Format PA Mode}

Using a three-dimensional diagram on transaction fees and third-party reseller service levels, we verified Theorem 2 . The results are as follows.

Figure 3 shows that the transaction fee and service level have an opposite influence on the wholesale price of the third-party reseller. When making a decision about the wholesale price for the E-tailer and the third-party reseller, the manufacturer will face different impacts from the above two factors. 

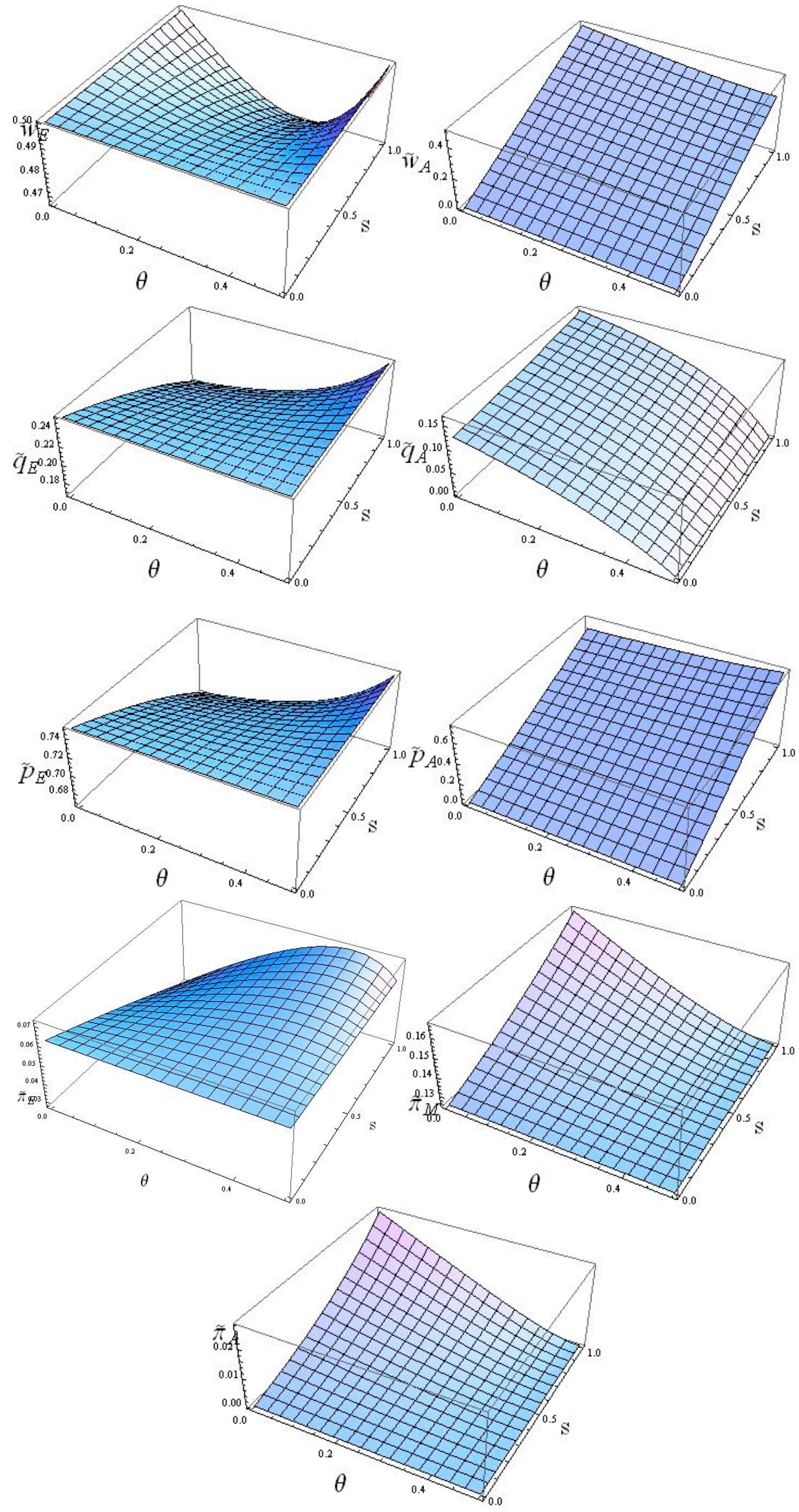

Figure 3. Equilibrium in Platform-Agent mode. 
Similar to the dual-format EM mode, the sales quantity reflects a complement of the characteristics under the influence of the transaction fee and service level. However, the product price varies based on the sales quantity's changing trends. The price increases as the transaction fee increases and decreases, while the service level increases. This shows that an increase in the third-party reseller's service level will not necessarily lead to severe market competition.

Next, we examine the profit of the players. Consistent with the manufacturer, the profit of the third-party reseller will decrease as the transaction fee increases and increase as the service level increases. Enhancing the service level is an efficient strategy for third-party resellers to increase their profits. However, the E-tailer faces complex circumstances when these two factors change. A pure strategy of increasing the transaction fee may not always be beneficial.

\subsection{Equilibrium Decision Comparison under the Three E-Retailing Modes}

Let $s=0.7$, with equilibrium decisions for the wholesale price, sales volume and product price under each E-retailing mode. We can have a clear comparison between wholesale prices, quantities, retail prices, respectively, in Figure 4.
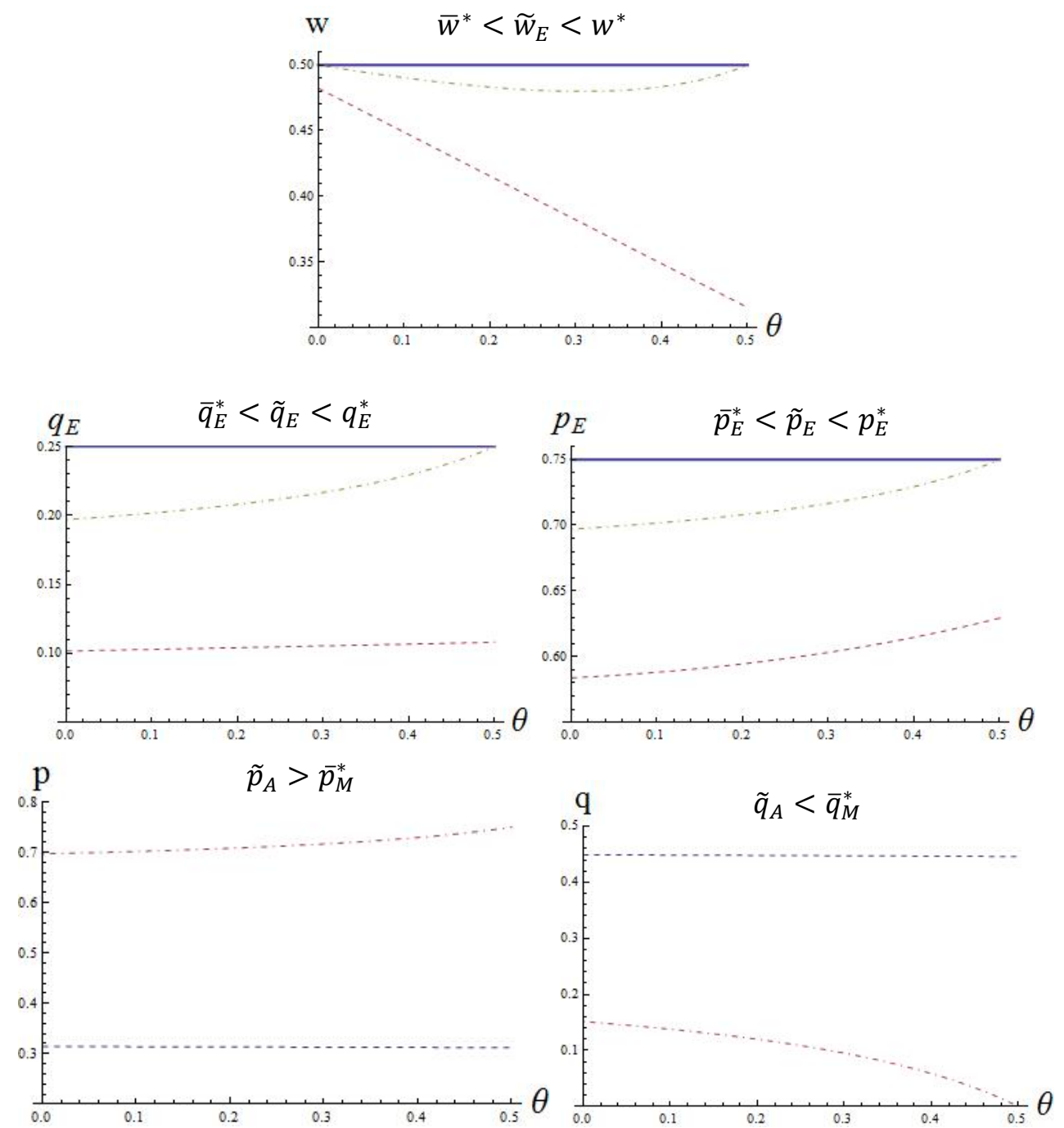

Figure 4. Equilibrium decision comparison under the three E-retailing modes. 
5.4. Profit Comparison under the Three E-Retailing Modes

In Figure 5, Area I shows $\pi_{E}^{*}<\tilde{\pi}_{E}^{*}<\bar{\pi}_{E}^{*} ;$ Area II shows $\pi_{E}^{*}<\bar{\pi}_{E}^{*}<\tilde{\pi}_{E}^{*} ;$ Area III shows $\bar{\pi}_{E}^{*}<\pi_{E}^{*}<\tilde{\pi}_{E}^{*} ;$ and Area IV shows $\bar{\pi}_{E}^{*}<\tilde{\pi}_{E}^{*}<\pi_{E}^{*}$.

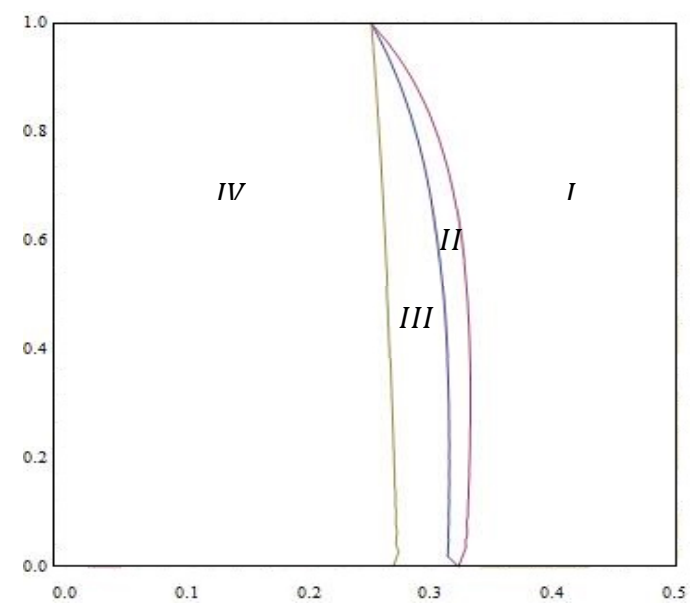

Figure 5. E-tailer's profit comparison under the three modes.

In Figure 6, Area I shows $\bar{\pi}_{M}^{*}<\pi_{M}^{*}<\tilde{\pi}_{M}^{*}$; Area II shows $\pi_{M}^{*}<\bar{\pi}_{M}^{*}<\tilde{\pi}_{M}^{*}$; and Area III shows $\pi_{M}^{*}<\tilde{\pi}_{M}^{*}<\bar{\pi}_{M}^{*}$

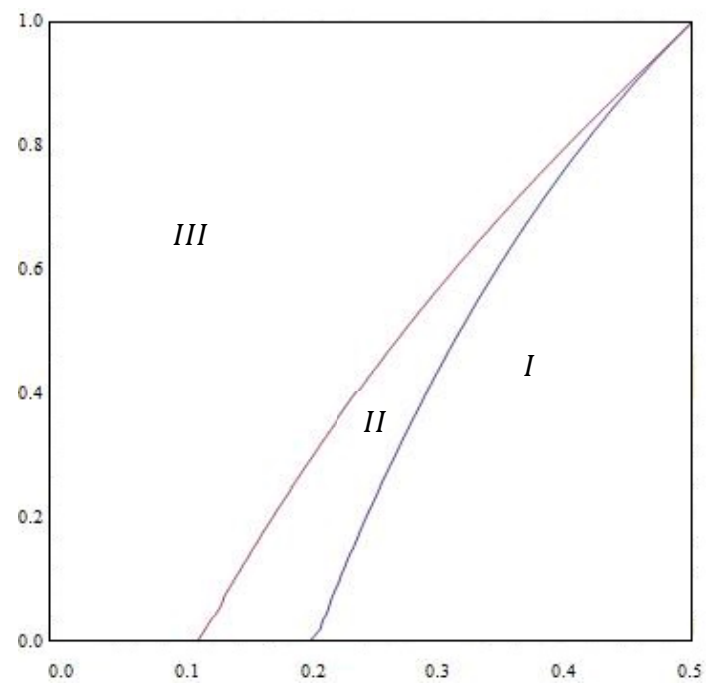

Figure 6. Manufacturer's profit comparison under the three modes.

In Figure 7, Area I shows $\pi_{M}^{*}>\bar{\pi}_{M}^{*}$ and $\pi_{E}^{*}<\bar{\pi}_{E}^{*}$; Area II shows $\pi_{M}^{*}>\bar{\pi}_{M}^{*}$ and $\pi_{E}^{*}>\bar{\pi}_{E}^{*}$; Area III shows $\pi_{M}^{*}<\bar{\pi}_{M}^{*}$ and $\pi_{E}^{*}>\bar{\pi}_{E}^{*}$; and Area IV shows $\pi_{M}^{*}<\bar{\pi}_{M}^{*}$ and $\pi_{E}^{*}<\bar{\pi}_{E}^{*}$.

Thus, the three parties will reach their equilibrium in area IV. The E-tailer will not open the platform in areas II and III. The manufacturer will not join the platform in area I. 


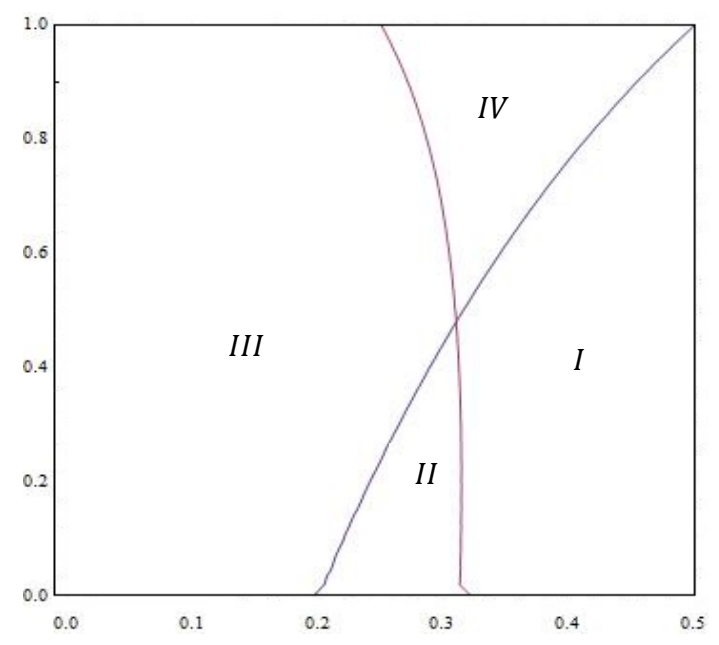

Figure 7. Profit comparison under the three E-retailing modes.

\section{Extension: An Unauthorized Third-Party Retailer}

The advantages produced by E-commerce benefit manufacturers by offering more open market opportunities. However, they also raise several real-world issues, including intellectual property, counterfeit problems and vicious competition. In order to seize the market and increase channel exposure in a short period of time, some platforms will use a low-price strategy to disrupt the market order, which sometimes will have a negative impact on the relevant brands. However, in real-world E-commerce, third-party sellers do not always have a commission from the original manufacturer. Various third-party resellers who may import their goods from different wholesalers participate in the online retail business. With the popularity of original equipment manufacture (OEM) and original design manufacture (ODM) some contract manufacturers found a new source of profit. Their actual production quantity exceeds the contract order's quantity. After they fulfill their orders, they distribute their surplus production through e-commerce channels. These surplus products and brand-name products are made by almost the same group of workers, production lines and plants. Selling through unauthorized e-channels can provide contract manufacturers a large amount of extra profit. Consumers only need to spend a portion of the authentic product's price to buy substitute products that are almost identical in quality and product variety. Indeed, consumers who buy an inauthentic product may be completely unaware their product's origins. As this phenomenon prevails, consumers' learning ability increases and they begin to acquire this cheaper purchasing behavior, which can seriously affect the image and interest of a brand. Major brands have consistently complained about and resisted the practice of E-commerce platforms acquiescing to unauthorized third-party retailers to sell their branded products. The famous jeweler Swarovski has also complained to e-commerce platforms for allowing other retailers to sell relevant goods that were not authorized by their company. Since there a large portion of profits come from the transaction fees paid by retailers, the platform company has less incentive to prohibit the appearance of unauthorized third-party sellers and prevent unauthorized selling.

For an unauthorized third-party, the wholesale price will be an exogenous variable. We consider an unauthorized third-party reseller selling through an E-tailer's marketplace and later compare the benefits achieved by the E-tailer from both an authorized and unauthorized third-party reseller. By comparing the two different distribution channel structures, we can clarify how the E-tailer and manufacturer prefer players to participate in the online platform marketplace. This result may shed substantial light on how an E-tailer configures the marketplace structure and regulates different contracts for the marketplace participants.

Let us denote $\hat{\pi}_{A}$ as the payoff for an unauthorized third-party seller who sells on the E-tailer's marketplace. Let $\hat{w}_{A}$ be the wholesale price for the unauthorized third-party, $\hat{w}_{A}=\tilde{w}_{A}^{*}-\delta$. 
The wholesale price for the E-tailer under this scenario is $\hat{w}_{E^{\prime}}^{*} \hat{w}_{E}^{*}=\tilde{w}_{E}^{*}-\frac{2 \delta}{4(1-\theta)}$. Following the same gaming process used in Mode EA, we determine that when $\theta \leq \frac{1}{2}$, we always have $\hat{\pi}_{M}^{*}-\tilde{\pi}_{M}^{*}=-\frac{4(1-\theta)-s}{2 s(1-\theta)^{2}\{4-s(1+\theta)\}} \delta^{2}<0$. Thus, in this case, the manufacturer will not prefer to have an unauthorized third-party play in the marketplace. He will always choose to directly sell products or authorize a third-party to sell in the marketplace. This conclusion accurately reflects the real E-commerce environment. Manufacturers frequently complain to the platform provider to limit the number of authorized dealers not only to resist the possibility of counterfeits but also for these beneficial issues. By examining the E-tailer's situation, we found the E-tailer may be better off in the unauthorized scenario. Specifically, when $0 \leq \delta \leq \min \left\{\frac{2 s(1-\theta)\{4-s(1+\theta)\}\{4(2-\theta)-s(5-s)\}}{\{4(1-\theta)-s\}\left\{s^{2}-4 s(2+\theta)+16\right\}}, \hat{w}_{A}\right\}$, the E-tailer's payoff under the unauthorized scenario will be higher than the payoff under Mode EA. This result explains why platform providers sometimes turn a blind eye to manufacturers' complaints: under some conditions, platform providers will gain more profit if there is an unauthorized third-party in the channel structure.

\section{Conclusions}

In this paper, we have analyzed the channel structure and supply chain of prevalent E-tailer-based online retailing channels. Online channel competition initiates between the E-tailer and the manufacturer (PM mode) or between the E-tailer and third-party retailer (PA mode). We have developed game theory models for different online competition scenarios arising from E-tailer and manufacturer channel expansions. Our analytical results have shown that the transaction fee charged by the platform and the service level provided to customers play significant roles in deciding the marketplace's business strategy. A pure strategy of raising the transaction fee may not always be beneficial and a competitor's superior service level may help increase the rivals' sales prices. Service level is thus a complementary strategy with price. Our results provide a sound explanation for the E-tailer's operational strategy and the manufacturer's expansion strategy under different supply chain structures. Our models are foundational and the results are easy to understand. However, our findings are by no means self-evident.

Chinese e-commerce has existed for 17 years since the founding of Taobao, the largest e-commerce platform in China. In these 17 years, many business models have emerged to lead the market. However, over time, only a few have survived. Taobao and JD.com are among the best and these two companies also represent the two most successful business models in the world today. Taobao is a pure platform provider, which only establishes a trading place and payment system for retailers and customers. The core business of Taobao is to provide support services to its two side users. Unlike Taobao, the latecomer, JD.com, has transitioned from an E-tailer to a dual-format Marketplace and will soon acquire other marketplaces' market shares to become the largest retailer in China. JD.com not only saw the potential of both selling and competing with retailers on a large customer-based platform but also foresaw the importance of providing order fulfillment services to other retailers. JD.com has built a full-coverage logistics network nationwide, with warehouses in 110 countries. The relationship between JD.com, manufacturers and retailers has transformed from pure competition to coordination and coexistence. Our findings provide theoretical explanations for this transformation. We also provide a vivid example of how well the JD.com's sustainable development strategy during a public emergency. JD.com's self-built logistics network and in-depth supplier cooperation help it stand out from other marketplace giants and the proper utilization of the assets in the business model provide a solid foundation for sustainable consumption.

Our study has some limitations. First, as we focused our attention on online channel competition in this paper, we were not able to reveal the impacts that a company's online channel strategies may have on its offline channels, which still dominate for most companies. Also, leading E-tailers are developing omnichannel retailing strategies to establish brick-and-mortar stores in top cities-for example, Fresh Hema by Alibaba and Amazon 4-star. Second, our results were obtained under the assumption that the operational costs of an E-tailer are zero. This may not fully apply to situations where there is 
a major difference in channel cost. Third, in reality, there may be more than two retailers selling an identical product on one platform simultaneously. The E-tailer, manufacturer, authorized third-party retailer and unauthorized third-party retailer will then compete simultaneously. We, however, only focused on dual online channel competition. Along the line of this study, future studies may be extended to multiple online and offline channel competitions. Empirical studies could also be performed on E-tailers' omnichannel operational strategies. It would also be of interest to investigate the competition between two dual-format marketplaces, such as the cases of the JD supermarket and the Tmall supermarket.

Author Contributions: Conceptualization and methodology, S.P.; writing-original draft preparation, S.P.; modeling and analysis, S.P. and Y.W.; writing - review and editing, Y.W. All authors have read and agreed to the published version of the manuscript.

Funding: This research received no external funding.

Acknowledgments: We thank all the reviewers for their constructive comments.

Conflicts of Interest: The authors declare no conflict of interest.

\section{References}

1. Lipsman, A. Global Ecommerce 2019. Available online: https://www.emarketer.com/content/globalecommerce-2019 (accessed on 17 October 2019).

2. Allen, L.; Cooperstein, D.M.; Yong, D.; Oum, D.; Lee, J. Channel Conflict Crumbles; Forrester Research, Inc.: Cambridge, MA, USA, 2000; pp. 1-16.

3. Verblow, B. Direct-To-Consumer (DTC) Brand Growth Will Boost Social Ad Spending (2 April 2019). Available online: https://go.forrester.com/blogs/direct-to-consumer-dtc-brand-growth-will-boost-social-ad-spending (accessed on 17 October 2019).

4. Mantin, B.; Krishnan, H.; Dhar, T. The strategic role of third-party marketplaces in retailing. Prod. Oper. Manag. 2014, 23, 1937-1949. [CrossRef]

5. Tsay, A.A.; Agrawal, N. Channel dynamics under price and service competition. Manuf. Serv. Oper. Manag. 2000, 2, 372-391. [CrossRef]

6. Bernstein, F.; Federgruen, A. Pricing and replenishment strategies in a distribution system with competing retailers. Oper. Res. 2003, 51, 409-426. [CrossRef]

7. Cattani, K.; Gilland, W.; Heese, H.S.; Swaminathan, J. Boiling frogs: Pricing strategies for a manufacturer adding a direct channel that competes with the traditional channel. Prod. Oper. Manag. 2006, 15, 40.

8. Dumrongsiri, A.; Fan, M.; Jain, A.; Moinzadeh, K. A supply chain model with direct and retail channels. Eur. J. Oper. Res. 2008, 187, 691-718. [CrossRef]

9. Chiang, W.K.; Chhajed, D.; Hess, J.D. Direct marketing, indirect profits: A strategic analysis of dual-channel supply-chain design. Manag. Sci. 2003, 49, 1-20. [CrossRef]

10. Wu, C.; Mallik, S. Cross sales in supply chains: An equilibrium analysis. Int. J. Prod. Econ. 2010, 126, 158-167. [CrossRef]

11. Boyaci, T. Competitive stocking and coordination in a multiple-channel distribution system. IIE Trans. 2005, 37, 407-427. [CrossRef]

12. Geng, Q.; Mallik, S. Inventory competition and allocation in a multi-channel distribution system. Eur. J. Oper. Res. 2007, 182, 704-729. [CrossRef]

13. Tsay, A.A.; Agrawal, N. Channel conflict and coordination in the e-commerce age. Prod. Oper. Manag. 2004, 13, 93-110. [CrossRef]

14. Hendershott, T.; Zhang, J. A model of direct and intermediated sales. J. Econ. Manag. Strategy 2006, 15, 279-316. [CrossRef]

15. Xiao, T.; Shi, J.J. Pricing and supply priority in a dual-channel supply chain. Eur. J. Oper. Res. 2016, 254, 813-823. [CrossRef]

16. Cai, G.G. Channel selection and coordination in dual-channel supply chains. J. Retail. 2010, 86, 22-36. [CrossRef]

17. Hsiao, L.; Chen, Y.J. Strategic motive for introducing internet channels in a supply chain. Prod. Oper. Manag. 2014, 23, 36-47. [CrossRef] 
18. Ha, A.; Long, X.; Nasiry, J. Quality in supply chain encroachment. Manuf. Serv. Oper. Manag. 2015, 18, 280-298. [CrossRef]

19. Matsui, K. When should a manufacturer set its direct price and wholesale price in dual-channel supply chains? Eur. J. Oper. Res. 2017, 258, 501-511. [CrossRef]

20. Batarfi, R.; Jaber, M.Y.; Zanoni, S. Dual-channel supply chain: A strategy to maximize profit. Appl. Math. Model. 2016, 40, 9454-9473. [CrossRef]

21. Zhang, P.; He, Y.; Shi, C.V. Retailer's channel structure choice: Online channel, offline channel or dual channels? Int. J. Prod. Econ. 2017, 191, 37-50. [CrossRef]

22. Nie, J.; Zhong, L.; Yan, H.; Yang, W. Retailers' distribution channel strategies with cross-channel effect in a competitive market. Int. J. Prod. Econ. 2019, 213, 32-45. [CrossRef]

23. Chen, K.-Y.; Kaya, M.; Özer, Ö. Dual sales channel management with service competition. Manuf. Serv. Oper. Manag. 2008, 10, 654-675. [CrossRef]

24. Yan, R.; Pei, Z. Retail services and firm profit in a dual-channel market. J. Retail. Consum. Serv. 2009, 16, 306-314. [CrossRef]

25. Modak, N.M.; Kelle, P. Managing a dual-channel supply chain under price and delivery-time dependent stochastic demand. Eur. J. Oper. Res. 2019, 272, 147-161. [CrossRef]

26. Xu, H.; Liu, Z.Z.; Zhang, S.H. A strategic analysis of dual-channel supply chain design with price and delivery lead time considerations. Int. J. Prod. Econ. 2012, 139, 654-663. [CrossRef]

27. Qi, Q.; Wang, J.; Bai, Q. Pricing decision of a two-echelon supply chain with one supplier and two retailers under a carbon cap regulation. J. Clean. Prod. 2017, 151, 286-302. [CrossRef]

28. Xu, L.; Wang, C.; Zhao, J. Decision and coordination in the dual-channel supply chain considering cap-and-trade regulation. J. Clean. Prod. 2018, 197, 551-561. [CrossRef]

29. McIntyre, D.P.; Srinivasan, A. Networks, platforms and strategy: Emerging views and next steps. Strateg. Manag. J. 2017, 38, 141-160. [CrossRef]

30. Bakos, Y. The emerging role of electronic marketplaces on the Internet. Commun. ACM 1998, 41, 35-42. [CrossRef]

31. Brunn, P.; Jensen, M.; Skovgaard, J. e-Marketplaces: Crafting A Winning Strategy. Eur. Manag. J. 2002, 20, 286-298. [CrossRef]

32. Wang, S.; Archer, N.P. Electronic marketplace definition and classification: Literature review and clarifications. Enterp. Inf. Syst. 2007, 1, 89-112. [CrossRef]

33. Täuscher, K.; Laudien, S.M. Understanding platform business models: A mixed methods study of marketplaces. Eur. Manag. J. 2018, 36, 319-329. [CrossRef]

34. Muzellec, L.; Ronteau, S.; Lambkin, M. Two-sided Internet platforms: A business model lifecycle perspective. Ind. Mark. Manag. 2015, 45, 139-150. [CrossRef]

35. Hagiu, A. Merchant or two-sided platform? Rev. Netw. Econ. 2007, 6. [CrossRef]

36. Ryan, J.K.; Sun, D.; Zhao, X. Competition and coordination in online marketplaces. Prod. Oper. Manag. 2012, 21, 997-1014. [CrossRef]

37. Hagiu, A.; Wright, J. Multi-sided platforms. Int. J. Ind. Organ. 2015, 43, 162-174. [CrossRef]

38. Abhishek, V.; Jerath, K.; Zhang, Z.J. Agency selling or reselling? Channel structures in electronic retailing. Manag. Sci. 2015, 62, 2259-2280. [CrossRef]

39. Tian, L.; Vakharia, A.J.; Tan, Y.; Xu, Y. Marketplace, Reseller or Hybrid: Strategic Analysis of an Emerging E-Commerce Model. Prod. Oper. Manag. 2018, 27, 1595-1610. [CrossRef]

40. Anderson, S.P.; Foros, Ø.; Kind, H.J. Competition for advertisers and for viewers in media markets. Econ. J. 2017, 128, 34-54. [CrossRef]

41. Wirl, F. Agency Model and Wholesale Pricing: Apple versus Amazon in the E-Book Market. Int. J. Econ. Bus. 2018, 25, 243-264. [CrossRef]

42. Wang, C.; Leng, M.; Liang, L. Choosing an online retail channel for a manufacturer: Direct sales or consignment? Int. J. Prod. Econ. 2018, 195, 338-358. [CrossRef]

(C) 2020 by the authors. Licensee MDPI, Basel, Switzerland. This article is an open access article distributed under the terms and conditions of the Creative Commons Attribution (CC BY) license (http://creativecommons.org/licenses/by/4.0/). 